$\begin{array}{llllllllllll}\text { J } & \text { O } & \text { II } & \mathbf{R} & \text { N } & \text { A } & \text { L } & & \text { O } & \text { F }\end{array}$

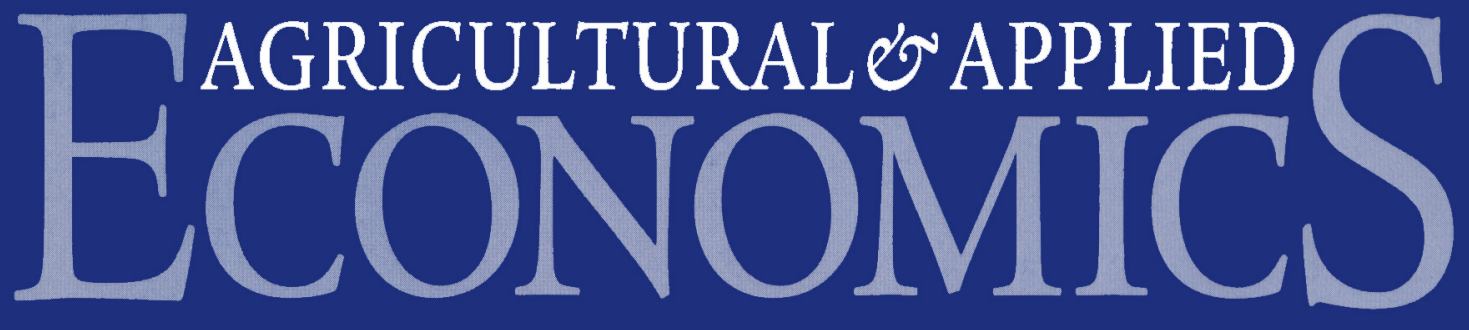

\title{
VOLIIIE 33
}

\section{Articles}

World Fibers Demand

Kenneth W. Clements and Yihui Lan

Turkey Demand Specification and Industry Structure

Laura M. Cheney, A. Blake Brown, Takashi Yamano, and Michael Masterovsky

Economic Efficiency in Organic Farming

Vangelis Tzouvelekas, Christos J. Pantzios, and Christos Fotopoulos

Economic Impacts of a Regional College of Veterinary Medicine

Binzhang Liu, Shukla Kshirsagar, Thomas Johnson, Craig Thatcher, and George W. Norton

An Assessment of Water Management Alternative Plans

Dhazn Gillig, Bruce A. McCarl, and Frederick Boadu

Cross-Hedging Strategies in the Broiler Industry

Leigh J. Maynard, Carl R. Dillon, and Joy Carter

Willingness to Pay

John C. Whitehead, Thomas J. Hoban, and William B. Clifford

Pre-Harvest Corn Pricing Strategies

Carl R. Zulauf, Donald W. Larson, Christopher K. Alexander, and Scott H. Irwin

Regulation in Quality Differentiated Markets

Jutta Roosen

Adult Equivalent Scales Revisited

Michael Demoussis and Vassili Mihalopoulos

Adoption of Pest-Management Practices

B. J. Hubbell, W. J. Florkowski, R. Oetting, S. K. Braman, and C. D. Robacker

Reactions to Compulsory Country-of-Origin Labeling

Alvin Schupp and Jeffrey Gillespie

Factors Affecting Potential Nitrogen Delivery

Wei Peng and Darrell J. Bosch

The "Complementarity Hypothesis" in Greek Agriculture

Constantinos P. Katrakilidis and Nikolaos M. Tabakis 


\title{
EDITORIAL STAFF
}

Editors

Charles B. Moss

The University of Florida
James L. Seale, Jr.

The University of Florida

Editorial Council

Barry Barnett
Mississippi State University
Gail L. Cramer
University of Arkansas
Stephen Davies
Colorado State University
Elias Dinopoulos
University of Florida
Allen Featherstone
Kansas State University
Bryan J. Hubbell
Environmental Protection Agency

Barry Barnett

Gail L. Cramer

University of Arkansas

Stephen Davies

Colorado State University

Elias Dinopoulos

University of Florida

Allen Featherstone

Kansas State University

Environmental Protection Agency

David W. Hughes
Louisiana State University
Kandice Kahl
Clemson University
Nicholas Kalaitzandonakes
University of Missouri
Michele C. Marra
North Carolina State University
Timothy Park
University of Georgia
Greg Pompelli
University of Tennessee
Xiang-Dong Qin
North Carolina A\&T University

David W. Hughes

Kandice Kahl

Clemson University

University of Missouri

Michele C. Marra

North Carolina State University

Timothy Park

University of Georgia

Greg Pompelli

Xiang-Dong Qin
Octavio Ramirez

Texas Tech University

Greg Traxler

Auburn University

Steven Vickner

University of Kentucky

Dave Weatherspoon

Michigan State University

Lois S. Willett

University of Florida

C. Thomas Worley

Washington State University

\section{Technical Editor \\ Wayne Losano, Ph.D.}

Department of English, University of Florida, Gainesville, FL 32611, (352) 392-6650 x249

\author{
Editorial Assistant \\ James C. Bassett \\ University of Florida
}

\section{EDITORIAL POLICY}

The Journal of Agricultural and Applied Economics (JAAE) provides a forum for creative and scholarly work in agricultural economics and related areas. Contributions on methodology and applications in business, extension, research, and teaching phases of agricultural and applied economics are equally encouraged. Submitted manuscripts are subject to peer review for publication consideration. Submission of critiques or comments on $J A A E$ articles are welcomed.

\section{EDITORIAL COMMUNICATIONS}

Manuscript submissions and editorial correspondence should be addressed to: Charles B. Moss or James L. Seale, Jr., Editors, JAAE, Post Office Box 110245, University of Florida, Gainesville, FL 32611-0240. Phone: (352) 392-1845 x404 or x414, fax: (352) 392-3646, e-mail: JAAE@ufl.edu.

The Journal of Agricultural and Applied Economics (ISSN 1074-0708) is published in April, August, and December by the Southern Agricultural Economics Association (SAEA). Visit our worldwide web site at http://www.agecon.uga.edu/ jaae/.

Copyright (C) 2001 by the Southern Agricultural Economics Association. Any article or other material published in the $J A A E$ may not be resubmitted for publication or republished elsewhere in full or in part without the written permission of the editors. 

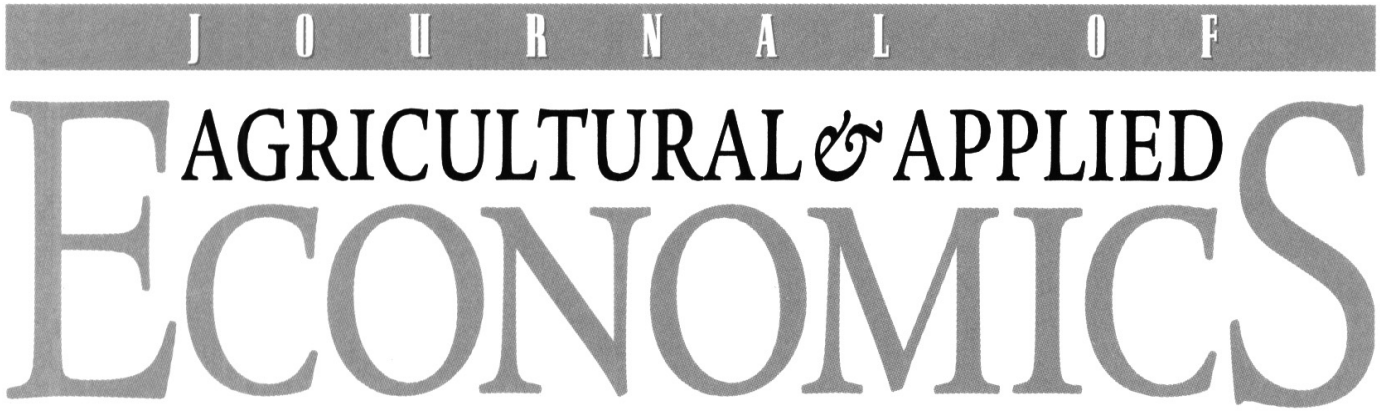

\section{VIILIME 33}

$$
\text { APRIL 2001 }
$$

NIIMRER 1

\section{Articles}

World Fibers Demand / Kenneth W. Clements and Yihui Lan

Issues of Demand Specification and Industry Structure in Turkeys and Broiler Chickens /

Laura M. Cheney, A. Blake Brown, Takashi Yamano, and Michael Masterovsky.

Economic Efficiency in Organic Farming: Evidence from Cotton Farms in Viotia, Greece /

Vangelis Tzouvelekas, Christos J. Pantzios, and Christos Fotopoulos

Evaluating the Short- and Long-run Economic Impacts of the Virginia-Maryland Regional College of Veterinary Medicine / Binzhang Liu, Shukla Kshirsagar, Thomas Johnson, Craig Thatcher, and George W. Norton

An Economic, Hydrologic, and Environmental Assessment of Water Management Alternative Plans for the South Central Texas Region / Dhazn Gillig, Bruce A. McCarl, and Frederick Boadu .... .

Go Ahead, Count Your Chickens: Cross-Hedging Strategies in the Broiler Industry /

Leigh J. Maynard, Carl R. Dillon, and Joy Carter

Willingness to Pay for Agricultural Research and Extension Programs /

John C. Whitehead, Thomas J. Hoban, and William B. Clifford

Pre-Harvest Pricing Strategies in Ohio Corn Markets: Their Effect on Returns and Cash Flow /

Carl R. Zulauf, Donald W. Larson, Christopher K. Alexander, and Scott H. Irwin

Regulation in Quality Differentiated Markets: Pesticide Cancellations in U.S. Apple Production /

Jutta Roosen

Adult Equivalent Scales Revisited / Michael Demoussis and Vassili Mihalopoulos

Implications of Lawn Care and Landscape Maintenance Firm Profiles for Adoption of Pest-Management Practices / B. J. Hubbell, W. J. Florkowski, R. Oetting, S. K. Braman, and C. D. Robacker

Handler Reactions to Potential Compulsory Country-of-Origin Labeling of Fresh or Frozen Beef / Alvin Schupp and Jeffrey Gillespie 
Risk and Site Factors Affecting Potential Nitrogen Delivery in the Virginia Coastal Plain /

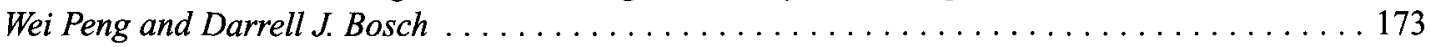

Investigating the "Complementarity Hypothesis" in Greek Agriculture: An Empirical Analysis /

Constantinos P. Katrakilidis and Nikolaos M. Tabakis 